Molecules 2008, 13, 1696-1701; DOI: 10.3390/molecules13081696

\title{
molecules
}

ISSN 1420-3049

www.mdpi.org/molecules

Article

\section{New Acetylenic Norlignan Compounds from Rhizomes of Curculigo crassifolia}

\author{
Kai-jin Wang ${ }^{1}$, Ning $\mathrm{Li}^{1, *}$ and $\mathrm{Hu}$ Wang $^{2}$
}

${ }^{1}$ College of Life Sciences, Anhui University, Hefei 230039, P. R. China; E-mail: wkjahla@sina.com (Kai-jin Wang)

2 Modern Experiment Technology Center, Anhui University, Hefei 230039, P. R. China;

E-mail: wanghu@ahu.edu.cn (Hu Wang)

* Author to whom correspondence should be addressed. E-mail:1n0110@sina.com;

Tel.: +86-551-5107341; Fax: +86-551-5107354.

Received: 13 June 2008; in revised form: 1 August 2008 / Accepted: 6 August 2008 / Published: 13 August 2008

\begin{abstract}
Two pairs of diastereoisomeric acetylenic norlignan compounds with $\mathrm{PhCH}\left(\mathrm{OR}_{1}\right) \mathrm{CH}\left(\mathrm{OR}_{2}\right) \mathrm{CH}_{2} \mathrm{C} \equiv \mathrm{CPh}$ skeleta: $(1 R, 2 R)-1-O$-methylnyasicoside (1) and $(1 S$, 2R)-1-O-methylnyasicoside (2), and (1R, 2R)-crassifogenin $\mathrm{D}(\mathbf{3})$ and $(1 S, 2 R)$ crassifogenin D (4), were isolated from the ethanolic extract of rhizomes of Curculigo crassifolia. Compounds $\mathbf{3}$ and $\mathbf{4}$ are new and their structures were elucidated on the basis of spectroscopic evidence and comparisons with literature data.
\end{abstract}

Keywords: Curculigo crassifolia; Hypoxidaceae; acetylenic norlignan compounds

\section{Introduction}

Curculigo crassifolia (Bak.) Hook. $\mathrm{f}$. belongs to the Hypoxidaceae family and is found throughout the Western and Southern regions of China. Its rhizomes are used as a tonic and a folk medicine for treating child pneumonitis [1]. Despite the use of the rhizomes of this plant as a folk remedy, reports on the chemical constituents of this plant are scarce [2-4]. In continuation of our studies on the norlignan constituents of the rhizomes of $C$. crassifolia, we now report that this plant is rich in 
acetylenic norlignan compounds and we describe the isolation and structural elucidation of two pairs of acetylenic norlignans and their corresponding glucosides: $(1 R, 2 R)-1-O$-methyl- nyasicoside (1) and $(1 S, 2 R)-1-O$-methylnyasicoside (2), and $(1 R, 2 R)$-crassifogenin $\mathrm{D}(\mathbf{3})$ and $(1 S, 2 R)$-crassifogenin D (4), which contain $\mathrm{PhCH}\left(\mathrm{OR}_{1}\right) \mathrm{CH}\left(\mathrm{OR}_{2}\right) \mathrm{CH}_{2} \mathrm{C} \equiv \mathrm{CPh}$ moieties (Figure 1).

\section{Results and Discussion}

The 95\% EtOH extract of air-dried and powdered rhizomes of C. crassifolia was suspended in $\mathrm{H}_{2} \mathrm{O}$ and then passed through D101 resin column eluting with $\mathrm{H}_{2} \mathrm{O}$ and EtOH. Further repeated column chromatography of the EtOH eluted residue on silica gel and Sephadex LH-20 led to the isolation of two pairs of acetylenic norlignan compounds with $\mathrm{PhCH}\left(\mathrm{OR}_{1}\right) \mathrm{CH}\left(\mathrm{OR}_{2}\right) \mathrm{CH}_{2} \mathrm{C} \equiv \mathrm{CPh}$ skeletons. Among them, the known compounds 1 and $\mathbf{2}$ were identified as $(1 R, 2 R)-1-O$-methylnyasicoside and $(1 S$, $2 R$ )-1-O-methylnyasicoside by comparing their physical and spectroscopic data with literature values $[5,6]$.

Table 1. ${ }^{1} \mathrm{H}-\mathrm{NMR}\left(400 \mathrm{MHz}, \delta\right.$ in ppm, $J$ in $\mathrm{Hz}$ ) data for compounds 1-4 in $\mathrm{CD}_{3} \mathrm{OD}$.

\begin{tabular}{lllll}
\hline NO. & $\mathbf{1}$ & $\mathbf{2}$ & $\mathbf{3}$ & $\mathbf{4}$ \\
\hline 1 & $4.38 \mathrm{~d}(6.28)$ & $4.47 \mathrm{~d}(3.76)$ & $4.08 \mathrm{~d}(8.20)$ & $4.09 \mathrm{~d}(3.40)$ \\
2 & $4.14 \mathrm{~m}$ & $4.14 \mathrm{~m}$ & $3.82 \mathrm{~m}$ & $3.75 \mathrm{~m}$ \\
3 & $2.70 \mathrm{dd}(17.12,4.76)$ & $2.56 \mathrm{dd}(13.84,5.28)$ & $2.46 \mathrm{dd}(16.65,4.30)$ & $2.46 \mathrm{dd}(16.65,4.30)$ \\
& $2.30 \mathrm{dd}(17.12,5.20)$ & $2.30 \mathrm{dd}(13.84,4.56)$ & $2.20 \mathrm{dd}(16.65,5.95)$ & $2.20 \mathrm{dd}(16.65,5.95)$ \\
$2^{\prime}$ & $6.89 \mathrm{~d}(1.44)$ & $6.89 \mathrm{~d}(1.44)$ & $6.87 \mathrm{~d}(1.50)$ & $6.87 \mathrm{~d}(1.50)$ \\
$5^{\prime}$ & $6.81 \mathrm{~d}(8.16)$ & $6.81 \mathrm{~d}(8.16)$ & $6.80 \mathrm{~d}(8.00)$ & $6.80 \mathrm{~d}(8.00)$ \\
$6^{\prime}$ & $6.75 \mathrm{dd}(8.16,1.44)$ & $6.75 \mathrm{dd}(8.16,1.44)$ & $6.75 \mathrm{dd}(8.00,1.50)$ & $6.75 \mathrm{dd}(8.00,1.50)$ \\
$2^{\prime \prime}$ & $6.87 \mathrm{~d}(1.58)$ & $6.87 \mathrm{~d}(1.58)$ & $6.82 \mathrm{~d}(2.00)$ & $6.82 \mathrm{~d}(2.00)$ \\
$5^{\prime \prime}$ & $6.71 \mathrm{~d}(8.12)$ & $6.71 \mathrm{~d}(8.12)$ & $6.71 \mathrm{~d}(8.08)$ & $6.71 \mathrm{~d}(8.08)$ \\
$6^{\prime \prime}$ & $6.80 \mathrm{dd}(8.12,1.58)$ & $6.80 \mathrm{dd}(8.12,1.58)$ & $6.78 \mathrm{dd}(8.08,2.00)$ & $6.78 \mathrm{dd}(8.08,2.00)$ \\
OMe & $3.25 \mathrm{~s}$ & $3.37 \mathrm{~s}$ & $3.18 \mathrm{~s}$ & $3.18 \mathrm{~s}$ \\
Glc. & & & & \\
1 & $4.63 \mathrm{~d}(7.56)$ & $4.60 \mathrm{~d}(7.80)$ & & \\
2 & $3.30-3.42 \mathrm{~m}$ & $3.30-3.42 \mathrm{~m}$ & & \\
3 & $3.30-3.42 \mathrm{~m}$ & $3.30-3.42 \mathrm{~m}$ & & \\
4 & $3.30-3.42 \mathrm{~m}$ & $3.30-3.42 \mathrm{~m}$ & & \\
5 & $3.30-3.42 \mathrm{~m}$ & $3.30-3.42 \mathrm{~m}$ & & \\
6 & $3.89 \mathrm{dd}(11.84,2.00)$ & $3.89 \mathrm{dd}(11.84,2.00)$ & & \\
& $3.70 \mathrm{dd}(11.84,5.32)$ & $3.70 \mathrm{dd}(11.84,5.32)$ & & \\
\hline & & & & \\
& & & \\
\end{tabular}

Compound $1,[\alpha]_{\mathrm{D}}^{28}+26.50^{\circ}$ (c $\left.0.16, \mathrm{MeOH}\right)$, was obtained as a white amorphous powder and assigned a molecular formula of $\mathrm{C}_{24} \mathrm{H}_{28} \mathrm{O}_{11}$ on the basis of the HRFAB-MS (-) ( $\mathrm{m} / z$ 491.1565 [M-1]', calcd. 491.1553). The IR absorption at $3441 \mathrm{~cm}^{-1}$ indicated the presence of hydroxyl groups. The ${ }^{1} \mathrm{H}-\mathrm{NMR}$ spectrum displayed signals for six aromatic protons in two ABX systems, and seven sugar protons, in addition to signals for four aliphatic protons at $\delta 4.38(\mathrm{~d}, \mathrm{H}-1), 4.14(\mathrm{~m}, \mathrm{H}-2), 2.30$ (dd, $\mathrm{H}-3$ ), and 2.70 (dd, H-3). Both sets of ABX systems, one at 6.89 (d, $\left.J=1.44 \mathrm{~Hz}, \mathrm{H}-2^{\prime}\right), 6.81(\mathrm{~d}, J=$ $\left.8.16 \mathrm{~Hz}, \mathrm{H}-5^{\prime}\right)$, and $6.75\left(\mathrm{dd}, J=8.16,1.44 \mathrm{~Hz}, \mathrm{H}-6^{\prime}\right)$ and the other at $6.87\left(\mathrm{~d}, J=1.58 \mathrm{~Hz}, \mathrm{H}-2^{\prime \prime}\right), 6.71$ 
(d, $J=8.12 \mathrm{~Hz}, \mathrm{H}-5 ")$, and 6.80 (dd, $J=8.12,1.58 \mathrm{~Hz}, \mathrm{H}-6 ")$, were consistent with two catechol-like moieties, with the latter being conjugated with a acetylene function $(\delta 84.4,83.7)$. Analysis of the signals of seven sugar protons suggested a $\beta$-D-glucosyl unit with the anomeric proton at $\delta 4.63(\mathrm{~d}, J=$ $7.56 \mathrm{~Hz}$ ). These assignments were made by analyzing the H-H COSY spectrum, incorporating HMQC data. The placement of $1-O$-methyl and $2-O-\beta-\mathrm{D}-\mathrm{Glc}$ was made from the observation of the three-bond coupling of $\mathrm{H}-1$ to $\mathrm{C}-1$ of the methyl group, anomeric proton to $\mathrm{C}-2$, and $\mathrm{H}-2$ to the anomeric carbon in the HMBC spectrum. The two remaining quaternary carbon signals $(\delta 84.4,83.7)$ belong to the acetylenic bond. The HMBC spectrum also revealed couplings of $\mathrm{H}-2$ and $\mathrm{H}-3$ to $\mathrm{C}-4, \mathrm{H}-2^{\prime}$ and $\mathrm{H}-6$ ' to C-5. Taking all these chemical shifts and their coupling relationships into consideration, the structure sequence of $\mathrm{PhCH}\left(\mathrm{OR}_{1}\right) \mathrm{CH}\left(\mathrm{OR}_{2}\right) \mathrm{CH}_{2} \mathrm{C} \equiv \mathrm{CPh}$ for $\mathbf{1}$ was arrived at, allowing the attachment of a methoxyl group at $\mathrm{C}-1$ position and the $\beta$-D-Glc moiety at the $\mathrm{C}-2$ position (Figure 1).

Figure 1. Structures of compounds 1-4.

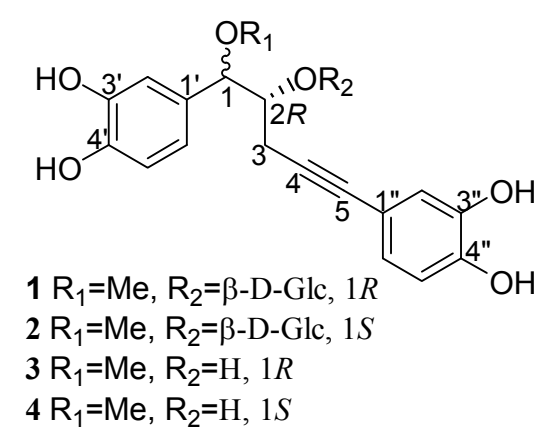

Since compound $\mathbf{1}$ is a nyasicoside-type norlignan from the Curculigo genus, from a biogenetic point of view, the C-2 stereochemistry in $\mathbf{1}$ should possess a $2 R$ configuration [6]. Further comparison of the coupling constant between $\mathrm{H}-1$ and $\mathrm{H}-2(6.28 \mathrm{~Hz})$ and the optical rotation $\left(+26.50^{\circ}\right)$ with literature values $[5,6]$, suggest $1 R$ and $2 R$ stereochemistry in $\mathbf{1}$. Hence, $\mathbf{1}$ is $(1 R, 2 R)-1-O$-methylnyasicoside.

Compound 2 was obtained as a white amorphous powder and assigned a molecular formula of $\mathrm{C}_{24} \mathrm{H}_{28} \mathrm{O}_{11}$ from its negative HRFAB-MS data. The ${ }^{1} \mathrm{H}$ - and ${ }^{13} \mathrm{C}-\mathrm{NMR}$ spectra showed that 2 was obtained in a ratio of 1:5 with compound 1. Most of the NMR signals of the mixture were in pairs. The ${ }^{1} \mathrm{H}$ - and ${ }^{13} \mathrm{C}-\mathrm{NMR}$ spectra of $\mathbf{2}$ are closely similar to that of $\mathbf{1}$, except for this difference of the coupling constant between $\mathrm{H}-1$ and $\mathrm{H}-2(\delta 4.38, \mathrm{~d}, J=6.28 \mathrm{~Hz}$ in 1 and $\delta 4.47, \mathrm{~d}, J=3.76 \mathrm{~Hz}$ in 2 ) (Table 1 and Table 2). For instance, 2 displayed signals for two ABX systems belonging to the aromatic protons, protons of a $\beta$-D-glucosyl moiety $(\delta 4.60$, d, $J=7.80 \mathrm{~Hz}, \mathrm{H}-1 ; \delta 3.30-3.42$, m, H-2-H-5; $\delta 3.89$, dd, $J=$ $2.00,11.84 \mathrm{~Hz}, \mathrm{H}-6 \mathrm{a} ; \delta 3.70, \mathrm{dd}, J=5.32,11.84 \mathrm{~Hz}, \mathrm{H}-6 \mathrm{~b})$, and four aliphatic protons at $\delta 4.47$ (d, $\mathrm{H}-1), 4.14$ (m, H-2), 2.30 (dd, H-3), and 2.56 (dd, H-3). These assignments were made by analyzing the H-H COSY spectrum, incorporating HMQC data. The placement of 1-O-methyl and 2-O- $\beta$-Glc was made from the observation of the three-bond coupling of $\mathrm{H}-1$ to methoxy carbon, anomeric proton to $\mathrm{C}-2$, and $\mathrm{H}-2$ to the anomeric carbon in the HMBC spectrum. The two remaining carbon signals $(\delta$ 84.7, 83.6) belong to the acetylenic bond. These data suggested that $\mathbf{2}$ and $\mathbf{1}$ possessed the same norlignan $\mathrm{PhCH}\left(\mathrm{OR}_{1}\right) \mathrm{CH}\left(\mathrm{OR}_{2}\right) \mathrm{CH}_{2} \mathrm{C} \equiv \mathrm{CPh}$ sequence. From a biogenetic point of view, the configuration of $\mathrm{C}-2$ in $\mathbf{2}$ should be $2 R$ [6]. Further comparing the coupling constant between $\mathrm{H}-1$ and $\mathrm{H}-2(3.76 \mathrm{~Hz})$ with literature values [6], this would require $1 S$ and $2 R$ stereochemistry in $\mathbf{2}$. Hence, 2 is 
$(1 S, 2 R)-1-O$ - methylnyasicoside.

Table 2. ${ }^{13} \mathrm{C}-\mathrm{NMR}\left(100 \mathrm{MHz}, \delta\right.$ in ppm) data for compounds $\mathbf{1 - 4}$ in $\mathrm{CD}_{3} \mathrm{OD}^{\mathrm{a}}$.

\begin{tabular}{ccccc}
\hline NO. & $\mathbf{1}$ & $\mathbf{2}$ & $\mathbf{3}$ & $\mathbf{4}$ \\
\hline 1 & $85.8 \mathrm{~d}$ & $85.6 \mathrm{~d}$ & $86.4 \mathrm{~d}$ & $87.0 \mathrm{~d}$ \\
2 & $79.5 \mathrm{~d}$ & $79.4 \mathrm{~d}$ & $73.9 \mathrm{~d}$ & $74.5 \mathrm{~d}$ \\
3 & $22.4 \mathrm{t}$ & $22.3 \mathrm{t}$ & $24.9 \mathrm{t}$ & $24.5 \mathrm{t}$ \\
4 & $84.4 \mathrm{~s}$ & $84.7 \mathrm{~s}$ & $85.6 \mathrm{~s}$ & $85.2 \mathrm{~s}$ \\
5 & $83.7 \mathrm{~s}$ & $83.6 \mathrm{~s}$ & $82.7 \mathrm{~s}$ & $82.8 \mathrm{~s}$ \\
$1^{\prime}$ & $130.4 \mathrm{~s}$ & $130.2 \mathrm{~s}$ & $131.3 \mathrm{~s}$ & $131.3 \mathrm{~s}$ \\
$2^{\prime}$ & $116.0 \mathrm{~d}$ & $116.0 \mathrm{~d}$ & $115.8 \mathrm{~d}^{\mathrm{a}}$ & $115.8 \mathrm{~d}^{\mathrm{a}}$ \\
$3^{\prime}$ & $145.8 \mathrm{~s}$ & $145.8 \mathrm{~s}$ & $145.6 \mathrm{~s}$ & $145.6 \mathrm{~s}$ \\
$4^{\prime}$ & $146.3 \mathrm{~s}$ & $146.3 \mathrm{~s}$ & $145.9 \mathrm{~s}$ & $145.9 \mathrm{~s}$ \\
$5^{\prime}$ & $116.0 \mathrm{~d}$ & $116.0 \mathrm{~d}$ & $115.9 \mathrm{~d}^{\mathrm{a}}$ & $115.9 \mathrm{~d}^{\mathrm{a}}$ \\
$6^{\prime}$ & $120.8 \mathrm{~d}$ & $120.6 \mathrm{~d}$ & $120.7 \mathrm{~d}$ & $120.2 \mathrm{~d}$ \\
$1^{\prime \prime}$ & $116.2 \mathrm{~s}$ & $116.2 \mathrm{~s}$ & $116.3 \mathrm{~s}$ & $116.3 \mathrm{~s}$ \\
$2^{\prime \prime}$ & $119.4 \mathrm{~d}$ & $119.4 \mathrm{~d}$ & $119.2 \mathrm{~d}$ & $119.2 \mathrm{~d}$ \\
$3^{\prime \prime}$ & $146.1 \mathrm{~s}$ & $146.1 \mathrm{~s}$ & $145.8 \mathrm{~s}$ & $145.8 \mathrm{~s}$ \\
$4^{\prime \prime}$ & $146.7 \mathrm{~s}$ & $146.7 \mathrm{~s}$ & $146.3 \mathrm{~s}$ & $146.3 \mathrm{~s}$ \\
$5^{\prime \prime}$ & $116.2 \mathrm{~d}$ & $116.2 \mathrm{~d}$ & $116.1 \mathrm{~d}$ & $116.1 \mathrm{~d}$ \\
$6^{\prime \prime}$ & $124.9 \mathrm{~d}$ & $124.9 \mathrm{~d}$ & $124.6 \mathrm{~d}$ & $124.6 \mathrm{~d}$ \\
OMe & $57.1 \mathrm{q}$ & $57.3 \mathrm{q}$ & $56.8 \mathrm{q}$ & $56.8 \mathrm{q}$ \\
Glc. & & & & \\
1 & $102.4 \mathrm{~d}$ & $102.7 \mathrm{~d}$ & & \\
2 & $74.7 \mathrm{~d}$ & $74.7 \mathrm{~d}$ & & \\
3 & $77.6 \mathrm{~d}$ & $77.6 \mathrm{~d}$ & & \\
4 & $71.3 \mathrm{~d}$ & $71.3 \mathrm{~d}$ & & \\
5 & $77.8 \mathrm{~d}$ & $77.8 \mathrm{~d}$ & & \\
6 & $62.6 \mathrm{t}$ & $62.6 \mathrm{t}$ & & \\
\hline & ${ }^{\prime}$ These values may be interchangeable in the same column. &
\end{tabular}

Although compound $\mathbf{1}$ was successfully purified, attempts to purify compound $\mathbf{2}$ failed. Reasons for this could be the small amount present and small differences in the interactions between this pair of diastereoisomers, and the column material used for their separation. Compounds $\mathbf{3}$ and $\mathbf{4}$ were assigned to $(1 R, 2 R)$-crassifogenin $\mathrm{D}(3)$ and $(1 S, 2 R)$-crassifogenin $\mathrm{D}(4)$; they had the same molecular formula of $\mathrm{C}_{18} \mathrm{H}_{18} \mathrm{O}_{6}$ on the basis of the HRFAB-MS (-) ( $\mathrm{m} / \mathrm{z} 329.1037$ [M-1]', calcd 329.1025). They were obtained as a 1:1 mixture, unresolvable by TLC and HPLC on account of the small amount obtained (only $4 \mathrm{mg}$, see Experimental). Most of the NMR signals of the mixture were in pairs. The ${ }^{1} \mathrm{H}-\mathrm{NMR}$ spectrum showed the presence of two 3,4-disubstituted aromatic rings. According to a selective ${ }^{1} \mathrm{H}$-decoupling experiment, incorporating HMQC and HMBC spectra, compounds $\mathbf{3}$ and $\mathbf{4}$ possessed the same norlignan $\mathrm{PhCH}\left(\mathrm{OR}_{1}\right) \mathrm{CH}\left(\mathrm{OR}_{2}\right) \mathrm{CH}_{2} \mathrm{C} \equiv \mathrm{CPh}$ sequence as compounds $\mathbf{1}$ and $2.1 \mathrm{D}$ and $2 \mathrm{D}$ NMR spectra showed that compounds 3 and $\mathbf{4}$ were aglycones of compounds $\mathbf{1}$ and $\mathbf{2}$, respectively. The $\delta$ values at C-2 in $\mathbf{3}$ and $\mathbf{4}$ were shifted upfield 5 - 6 compared to those of $\mathbf{1}$ and $\mathbf{2}$, while the $\delta$ values at $\mathrm{C}-1$ and $\mathrm{C}-3$ in $\mathbf{3}$ and $\mathbf{4}$ were downfield shifted, due to the absence of a $\beta$-D-glucose unit at $\mathrm{C}-2$. The $\delta$ values of remaining carbons in $\mathbf{3}$ and $\mathbf{4}$ were similar to the corresponding positions of $\mathbf{1}$ and 
2 (Table 2). The correlation peak between $\mathrm{C}-1$ and protons of $\mathrm{OCH}_{3}$ in the $\mathrm{HMBC}$ spectra of $\mathbf{3}$ and 4 confirmed that $\mathrm{OCH}_{3}$ was linked at $\mathrm{C}-1$. Compounds $\mathbf{3}$ and $\mathbf{4}$ are also nyasicoside-type norlignans, so from a biogenetic point of view, the C-2 stereochemistry in $\mathbf{3}$ and $\mathbf{4}$ should possess $2 R$ configuration [6]. Further comparing the coupling constant between $\mathrm{H}-1$ and $\mathrm{H}-2(8.20 \mathrm{~Hz}$ in $\mathbf{3}$, and $3.40 \mathrm{~Hz}$ in 4), this would require $1 R$ and $2 R$ stereochemistry in $\mathbf{3}$, and $1 S$ and $2 R$ stereochemistry in 4 . From the above results and comparison to those of compounds $\mathbf{1}$ and $\mathbf{2}$, the structures of $(1 R, 2 R)$-crassifogenin D (3) and $(1 S, 2 R)$-crassifogenin D (4) were established as aglycones of compounds $\mathbf{1}$ and 2. Compounds 3 and $\mathbf{4}$ were detected by RP-8 TLC in the EtOH extract, which showed $\mathbf{3}$ and $\mathbf{4}$ were not artifacts of $\mathbf{1}$ and $\mathbf{2}$ produced by the isolation procedure. Since compounds $\mathbf{3}$ and $\mathbf{4}$ were obtained as a $1: 1$ mixture of $(1 R, 2 R)$-crassifogenin $\mathrm{D}$ and $(1 S, 2 R)$-crassifogenin $\mathrm{D}$, the $(+)-(1 R, 2 R)$ optical rotation in 3 and the $(-)-(1 S, 2 R)$ one in 4 cancel each other out, and a zero optical rotation was observed for the mixture of 3 and 4 . On the other hand, the mixture of $\mathbf{1}$ and 2 was obtained in a ratio of 5:1, so the $(+)-(1 R, 2 R)$ configuration in 1 was predominant compared to the $(-)-(1 S, 2 R)$ one of the minor component $\mathbf{2}$, so an optical rotation of $+12.37^{\circ}$ was observed for the mixture of $\mathbf{1}$ and $\mathbf{2}$.

\section{Experimental}

\section{General}

The optical rotations were obtained on a JASCO-370 polarimeter. The UV spectra were recorded in $\mathrm{MeOH}$ on a UV-2401PC Spectrometer. The IR spectra were recorded on a Bio-Rad FTS-35 spectrometer using $\mathrm{KBr}$ pellets. The MS data were obtained on an Autospec-3000 spectrometer operating in negative ion mode. 1D and 2D NMR spectra were measured on a Bruker AM-400 or a Bruker DRX-500 spectrometer with TMS as an internal standard. Column chromatography was performed on Sephadex LH-20 (25-100 $\mu \mathrm{m}$, Pharmacia Fine Chemical Co. Ltd.) and silica gel (200-300 mesh, Qingdao Haiyang Chemical Co.). TLC was carried on silica gel G precoated plates (Qingdao Haiyang Chemical Co.) and spots were detected by 5\% sulfuric acid reagents followed by heating.

\section{Plant material}

The plant material was collected in Eshan Prefecture, Yunnan Province, China, in October 2002 and identified as Curculigo crassifolia by Prof. Ping-hua Yu, Kunming Institute of Botany, Chinese Academy of Science, where a voucher specimen (No. 20021018) was deposited.

\section{Extraction and isolation}

The air-dried and powered rhizomes of $C$. crassifolia $(10 \mathrm{~kg})$ were extracted with $95 \% \mathrm{EtOH}(3 \times 50$ L) at room temperature, then the combined extracts were evaporated in vacuo to afford a residue (562 g). The residue was suspended in $\mathrm{H}_{2} \mathrm{O}$ and then passed through D101 resin column eluting with $\mathrm{H}_{2} \mathrm{O}$ and $\mathrm{EtOH}$. The EtOH eluent was concentrated in vacuo to give a residue $(500 \mathrm{~g})$, which was fractionated by $\mathrm{CC}$ (silica gel, $3000 \mathrm{~g}, 200-300$ mesh; with $\mathrm{CHCl}_{3}-\mathrm{MeOH}, 9: 1$ ) to afford 5 fractions (1-5). Fraction 2 (13 g) was refractionated on a silica gel column $\left(220 \mathrm{~g}, \mathrm{CHCl}_{3}-\mathrm{MeOH}, 9.5: 0.5,1600\right.$ $\mathrm{mL})$ to provide 8 fractions (2-1 to $2-8)$. Fraction $2-4(210 \mathrm{mg}$ ) was purified by repeated Sephadex 
LH-20 chromatography (EtOH) to afford a mixture of $(1 R, 2 R)$-crassifogenin $D(3)$ and (1S, $2 R)$-crassifogenin $D(4)$ (4 mg): white amorphous powder. $[\alpha]_{\mathrm{D}}^{28}=0^{\circ}(c 0.12, \mathrm{MeOH}) ; \mathrm{UV}(\mathrm{MeOH})$ : $\lambda_{\max }(\lg \varepsilon): 205$ (4.56), 256 (4.08), 289 (3.77) nm; IR $v_{\max }: 3441,2924,1629,1517,1443,1283,1179$, 1111, 815, 583 $\mathrm{cm}^{-1} ;{ }^{1} \mathrm{H}-\mathrm{NMR}$ see Table $1,{ }^{13} \mathrm{C}-\mathrm{NMR}$ see Table 2; FAB-MS m/z: 329 [M-H]; HR-FABMS $m / z$ : [M-H] 329.1037 (calcd. for $\mathrm{C}_{18} \mathrm{H}_{17} \mathrm{O}_{6}, 329.1025$ ). Fraction 5 (210 g) was refractionated by Sephadex LH-20 (EtOH-H ${ }_{2} \mathrm{O}, 0: 1-1: 0 ; 2000 \mathrm{~mL}$ each eluent) to yield 12 crude fractions (5-1 to 5-12). Fraction 5-7 (4.34 g) was purified by Sephadex LH-20 (EtOH- $\mathrm{H}_{2} \mathrm{O}, 0: 1-1: 0 ; 700 \mathrm{ml}$ each eluent) to yield 6 fractions (5-7-1 to 5-7-6). Fraction 5-7-4 (612 mg) was repeatedly purified on Sephadex LH-20 (EtOH) to afford a mixture of $(1 R, 2 R)$-1-O-methylnyasicoside (1) and (1S, 2R)-1-O-methylnyasicoside (2) $(212 \mathrm{mg})$ and pure $1(18 \mathrm{mg})$. White amorphous powder; $[\alpha]_{\mathrm{D}}^{28}:+12.37^{\circ}(c 0.18, \mathrm{MeOH})$; UV (MeOH): $\lambda_{\max }(\lg \varepsilon): 205$ (4.34), 255 (3.96), 289 (3.65) nm. IR $v_{\max }: 3441,2926,2045,1546,1473$, $1179 \mathrm{~cm}^{-1} ;{ }^{1} \mathrm{H}-\mathrm{NMR}$ see Table $1 ;{ }^{13} \mathrm{C}-\mathrm{NMR}$ see Table 2; FAB-MS $m / z$ : 491 [M-H] ${ }^{-}$; HR-FAB-MS $m / z$ : [M-H] 491.1565 (calcd. for $\mathrm{C}_{24} \mathrm{H}_{27} \mathrm{O}_{11}, 491.1553$ ).

\section{Acknowledgements}

This work was funded by the National Natural Science Foundation of China (30670217), International Foundation for Science (F/4340-1), the Science and Technology Foundation of Distinguished Young Scholars of Anhui Province (08040106812) and the Innovative Research Team of 211 Project in Anhui University (02203104/04).

\section{References}

1. Institutum Botanicum Kunmingense, Academiae Sinicae. Flora Yunnanica; Wu C. Y., Ed.; Science Press: Beijing, 1995; Vol. 6, p. 819 (in Chinese).

2. Li, N.; Wang, K. J.; Chen, J. J.; Zhou, J. Two novel glucosyl-fused compounds from Curculigo crassifolia (Hypoxidaceae). Tetrahedron Lett. 2005, 46, 6445-6447.

3. Li, N.; Chen, J. J.; Zhou, J. Two New Phenolic Glycosides from Rhizomes of Curculigo crassifolia. Z. Naturforsch. B. 2006, 61b, 611-614.

4. Wang, K. J.; Li, N. Antioxidant Phenolic Compounds from Rhizomes of Curculigo crassifolia. Arch. Pharm. Res. 2007, 30, 8-12.

5. Chang, W. L.; Su, M. J.; Lee, S. S. Bioactive norlignan glucosides from Curculigo capitulata. J. Nat. Prod. 1997, 60, 76-80.

6. Chang, W. L.; Chen, C. H.; Lee, S. S. Three novel constituents from Curculigo capitulata and revision of C-2 stereochemistry in nyasicoside. J. Nat. Prod. 1999, 62, 734-739.

Sample Availability: Available from authors.

(C) 2008 by the authors; licensee Molecular Diversity Preservation International, Basel, Switzerland. This article is an open-access article distributed under the terms and conditions of the Creative Commons Attribution license (http://creativecommons.org/licenses/by/3.0/). 